\title{
Socioeconomic Inequalities in Childhood Obesity in the United Kingdom: A Systematic Review of the Literature
}

\author{
Abdulrahman M. El-Sayed ${ }^{a, b, c}$ Peter Scarborough ${ }^{a} \quad$ Sandro Galea ${ }^{b}$ \\ a Department of Public Health, University of Oxford, Oxford, UK, b Department of Epidemiology, \\ Columbia University, New York, NY, 'College of Physicians and Surgeons, Columbia University, \\ New York, NY, USA
}

\section{Key Words}

Obesity $\cdot$ Child $\cdot$ Pediatric $\cdot$ Poverty $\cdot$ Deprivation $\cdot$ Socioeconomic status $\cdot$ Socioeconomic position $\cdot$ United Kingdom $\cdot$ England $\cdot$ Wales $\cdot$ Scotland

\begin{abstract}
Childhood obesity is a major public health challenge worldwide. There is a growing literature documenting socioeconomic inequalities in childhood obesity risk. Here we draw inference from the literature about inequalities in childhood obesity risk in the UK. We summarize and appraise the extant peer-reviewed literature about socioeconomic inequalities in childhood obesity in the UK. Common area-level indices of socioeconomic position, including the Carstairs Deprivation Index, the Index of Multiple Deprivation and the Townsend Deprivation Index, as well as common household and individual-level metrics of childhood socioeconomic position, including head-of-household social class and maternal education, were generally inversely associated with childhood obesity in the UK. We summarize key methodological limitations to the extant literature and suggest avenues for future research.
\end{abstract}

Copyright (c) 2012 S. Karger GmbH, Freiburg

\section{Introduction}

Childhood obesity is a growing worldwide epidemic [1]. Recent research about trends in global childhood overweight and obesity over the last several decades have demonstrated increases in almost all countries for which data is available [2, 3]. According to the World Health Organization (WHO), 42 million children under the age of 5 were overweight in the 
year 2010 worldwide [4], and available evidence suggests that up to $79 \%$ of these children will progress to overweight and obesity in adulthood [5-7]. Obesity has important social and psychological consequences among children and adolescents, as it has been shown to predict abuse from peers among children and depression among adolescents [8,9]. Moreover, as an important determinant of chronic disease risk and mortality in childhood and adulthood, childhood obesity is a looming threat to the public's health [10-20].

Socioeconomic position (SEP) is a measure of the structural location of individuals with respect to access to resources relative to others in a society [21]. In their work on fundamental causes, Link and Phelan [22] contend that lower SEP will always predict worse health, as SEP portends access to health-promoting resources, even as those resources may change over time. Poor SEP is a well-known predictor of adverse health outcomes among diverse populations.

There is a large literature that has demonstrated inequalities in obesity in both highand low-income contexts worldwide - however, the direction of this association differs by economic context [23-25]. In high-income contexts, like the UK, there is a strong inverse association between metrics of SEP and obesity, whereas SEP and obesity are directly associated in low-income countries [23]. Moreover, with time, and as low-income countries have developed, there have been concomitant increases in obesity prevalence [26], as, for example, is taking place in China [27]. Research about socioeconomic inequalities in obesity among children worldwide has demonstrated similar trends [4, 25].

Already among the highest in the world, risk for childhood obesity is increasing in the UK $[28,29]$. Between 1995 and 2007, the rate of obesity in children aged 2-15 years in England increased from 12 to $17 \%$ [30]. Rising obesity rates among children have received considerable attention among public health officials. For example, they have substantiated recommendations to ban marketing toward children of unhealthy foods, and to allocate greater than $3 \mathrm{~h} /$ week for physical activity among children in schools in the UK [31, 32].

Several studies about health inequalities in the UK have demonstrated socioeconomic differences in self-rated health, heart disease, chronic bronchitis, smoking, diet, exercise, and overall mortality [33, 34]. A recent review about health inequalities in England highlighted SEP inequalities in morbidity, self-reported health, psychopathology, accidental injury, and mortality [35]. Studies also suggest widening inequalities in several important population health metrics in the UK, such as life expectancy and mortality rates between the early 1980 s and 2000 s $[35,36]$.

Several studies have suggested socioeconomic disparities in childhood obesity in the UK, with poor children at higher risk for obesity [37-43]. A recent report from the UK's National Obesity Observatory showed consistent inequalities in obesity among children at both reception year and year 6 by area-level deprivation, with some evidence of increasing inequalities among boys [44]. However, we know of no attempts to systematically appraise or synthesize findings regarding socioeconomic inequalities in obesity in this context.

Understanding socioeconomic inequalities in childhood obesity in the UK may yield important inferences about SEP inequalities in childhood obesity more broadly for several reasons. First, with a nationalized health system, public health research and policy in the UK are relatively centralized and unified. Therefore, the UK features several high-quality government-sponsored datasets that include information about childhood obesity, including the annual Health Survey for England, the Scottish Health Survey and the National Childhood Measurement Programme, as well as others. Moreover, UK health policy has been explicit about both addressing inequalities in health as well as childhood obesity, featuring national targets to reduce levels of overweight and obesity among children to below year 2000 levels by the year 2020 [45], and to eradicate childhood poverty by the year 2020 [46]. Moreover, in 2007, the National Obesity Observatory was established to 
monitor obesity in the UK, complementing several other initiatives in place to combat the childhood obesity epidemic, including the 'Food in Schools' program, the 'School Fruit and Vegetable Scheme', and the 'Physical Education, School Sport and Club Links Programme' [47], although these programs are under threat following recently established budget cuts. Second, despite the substantial attention to both childhood obesity as well as childhood poverty on the part of the UK government, there remain strong associations between metrics of SEP and child hood obesity in the UK [37-43]. Therefore, the UK presents an ideal opportunity to examine etiological mechanisms relating SEP and obesity among children, including the roles of ethnic minority socioeconomic segregation, individual versus arealevel production of socioeconomic inequalities, and the production of inequalities throughout the childhood life course.

Here, we review the extant peer-reviewed literature published in the past 30 years about socioeconomic disparities in childhood obesity. We summarize important differences in the prevalence and determinants of obesity by socioeconomic metrics in the UK, attempting to identify and isolate key indicators in the SEP environment likely to influence childhood obesity risk. Additionally, we comment on generalizable themes in this area of research, considering methodological limitations to the extant literature.

We reviewed the literature about socioeconomic inequalities in obesity in the UK so as to understand how SEP influenced obesity risk in the UK. We limited our review to the UK for several reasons. First, we were interested in ascertaining mechanisms that maintained SEP inequalities in the UK, and these mechanisms may plausibly differ across countries. Second, because national health systems may differ with regard to the relation between SEP and access to healthcare services as well as the focus placed on prevention within systems, generalizing across countries with regard to the relation between SEP and childhood obesity may not be warranted. Third, because of the correlation between ethnicity and SEP in highincome countries and because ethnic minority groups may have differential risk for childhood obesity than whites [48-52], countries with different proportions of ethnic minority groups may show different relations between SEP and obesity, precluding generalization across countries.

\section{Methods}

This review encompassed the peer-reviewed literature published between January 1 , 1980 and March 8, 2010. We limited our review to these years so as to reflect current thinking about the relation between SEP and health. We identified the literature reviewed through the MEDLINE database using the 'pubmed.gov' interface, and it included papers that included any empirical assessment of the relation between metrics of SEP and metrics of obesity. We used MeSH search terms 'Obesity' and 'Great Britain' for English-language articles published in the peer-reviewed literature. All queries were carried out by the primary author during the month of March, 2010.

Our original search yielded 1,189 articles, 233 of which were judged to consider the relation between SEP and obesity in the UK after screening by title. Upon screening by abstract for empirical articles set in the UK, we were left with 102 articles. After reading the remaining articles, another 54 were discarded because they did not meet the following criteria: i) considered differences in outcomes by at least one defined metric of SEP and described attribution of SEP metrics among respondents; ii) described the method used to define obesity, including metric of interest, and threshold for overweight or obesity utilized in analysis; and iii) conducted a direct empiric analysis of differences in obesity outcome by metric of SEP. Reference lists from these articles were searched, and yielded a further 10 


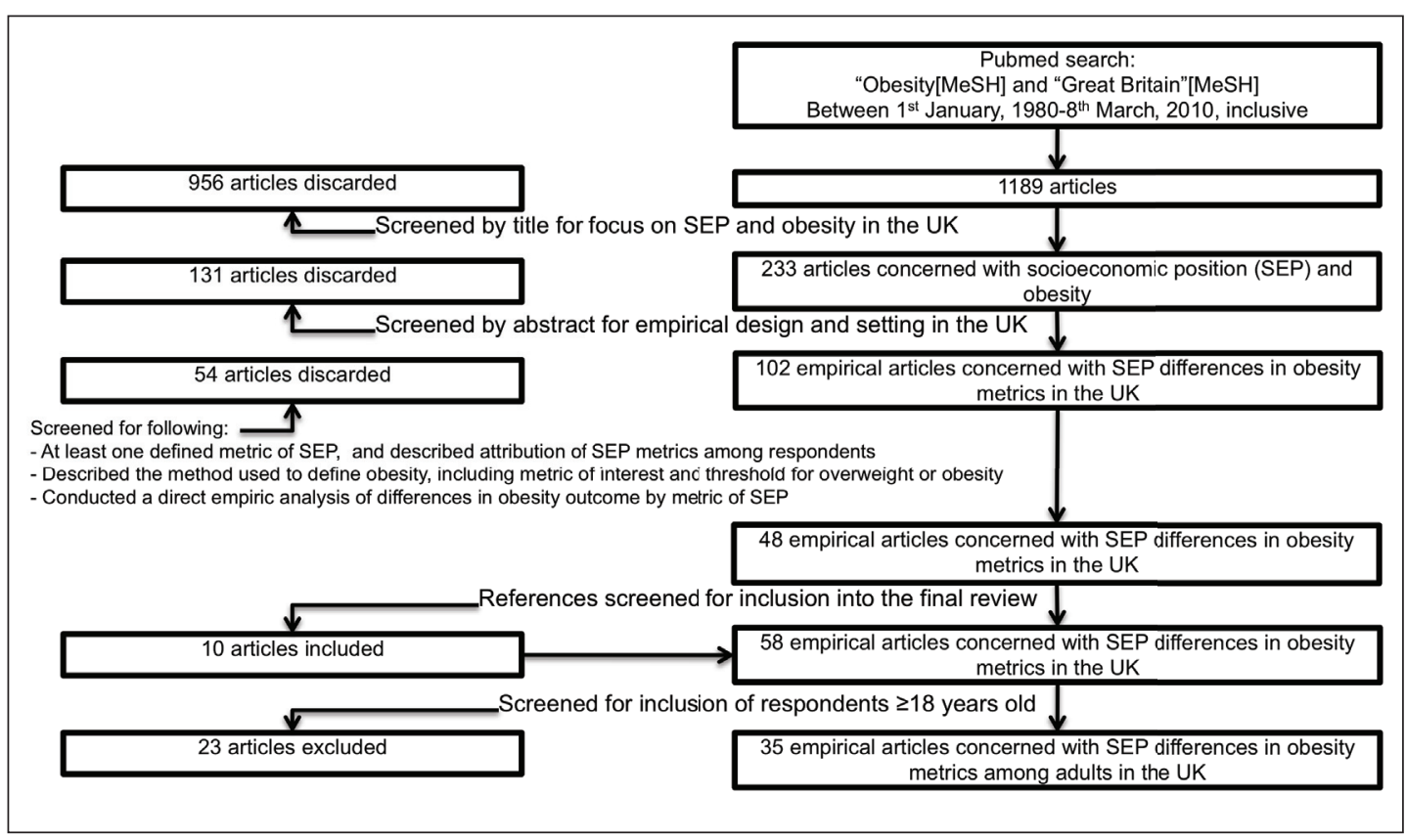

Fig. 1. Search strategy: Socioeconomic inequalities in childhood obesity in the UK.

articles which fulfilled the inclusion criteria, yielding a total of 58 articles. Finally, 35 articles that did not include outcome measures among respondents under the age of 18 years were excluded, yielding a total of 23 articles reviewed here. A diagram of the search strategy employed in the present article is shown in figure 1.

For each of these papers, the primary author extracted the following information: SEP metric(s); definition of obesity; population and setting; sample and methods; findings and conclusions. The use of 20 different area-level and individual/household-level metrics to measure SEP as well as of 17 different metrics for obesity in the studies reviewed here precluded meta-analysis of the results.

\section{Results}

The studies considered in this review utilized two empirical study designs: 5 studies included in this review were longitudinal analyses, while the remaining 18 were crosssectional in nature. There were 20 different metrics used to ascertain child SEP as well as 17 different metrics used to measure childhood obesity. Only three studies included socioeconomic metrics collected at multiple levels (area-level, household/individual-level), and none of these studies utilized multilevel or complex systems approaches during analysis. None of the studies reviewed assessed mechanisms that mediated socioeconomic inequalities in obesity risk in the UK.

Eight of the studies we report on here used data from regional datasets from localities throughout the UK (London, Peterborough, etc.). The remaining studies reported on representative data from at least one country in the UK. Five studies reported findings from Northern Ireland; there were 7 studies that reported on data from Wales; 10 reported on data from Scotland; and 18 studies reported on data from England (table 1). 


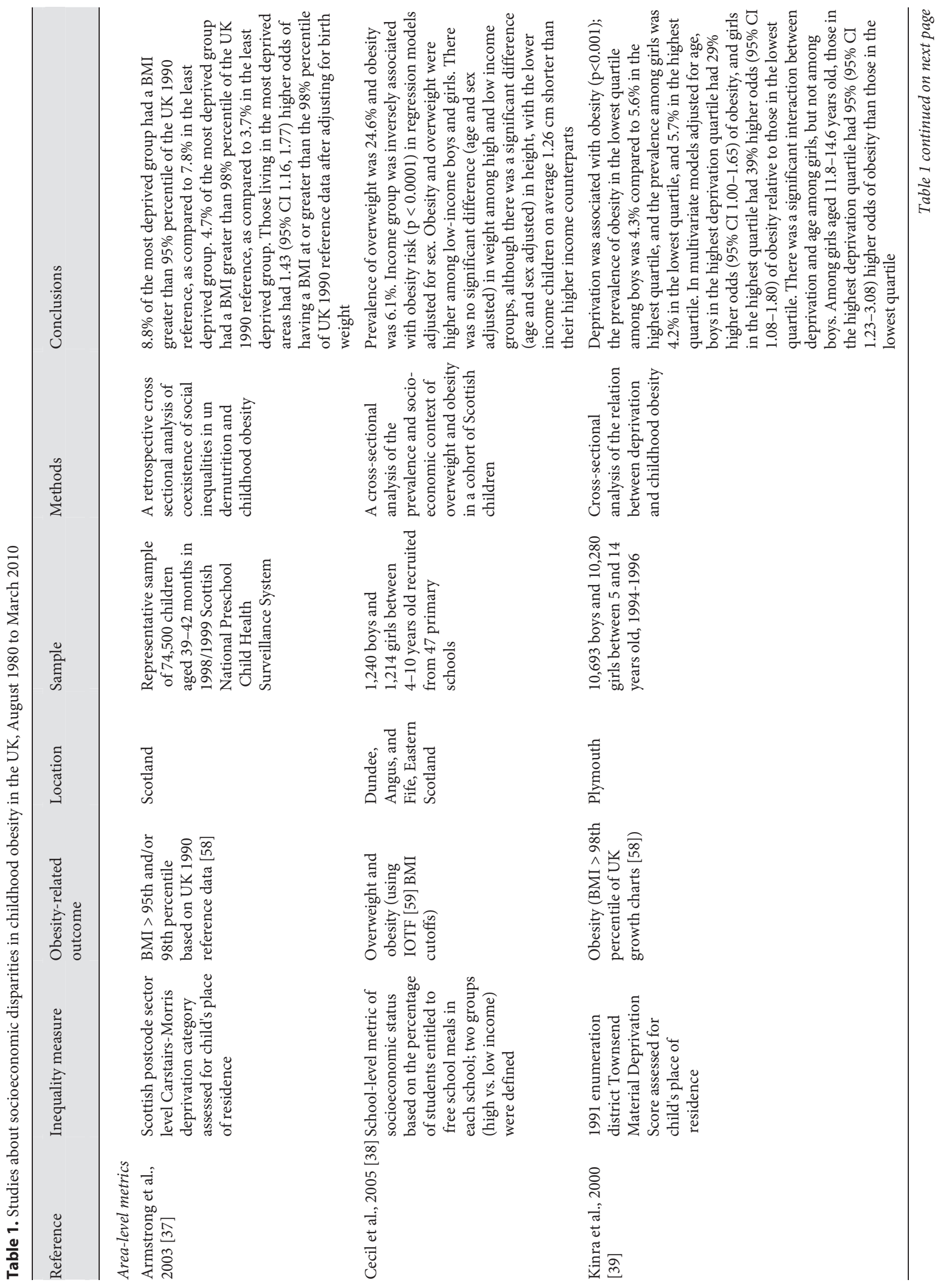




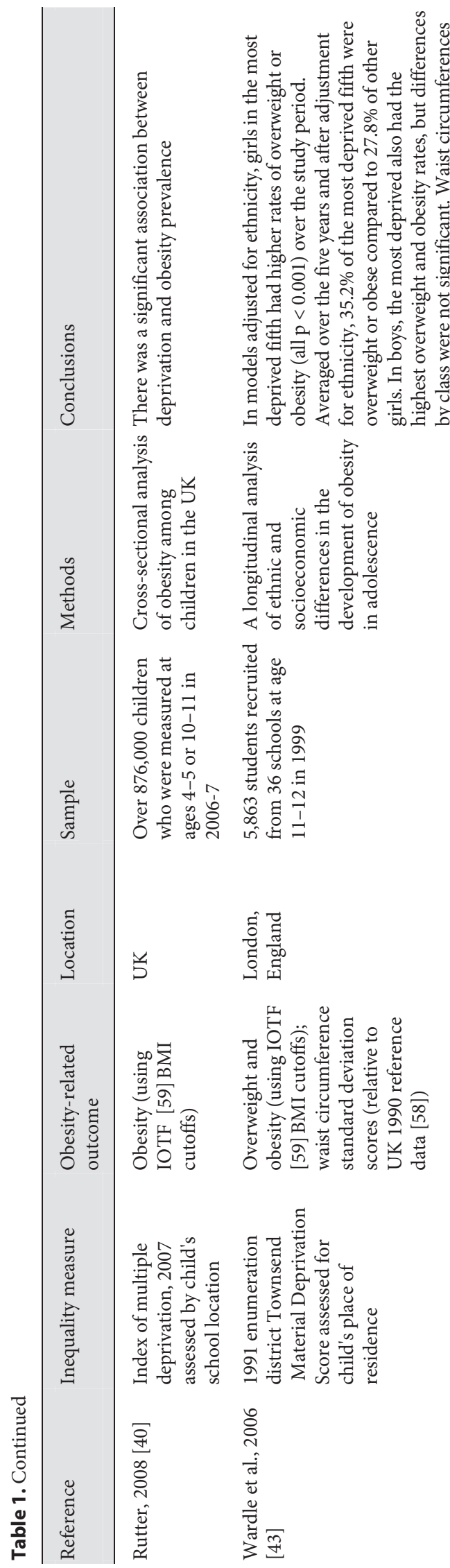

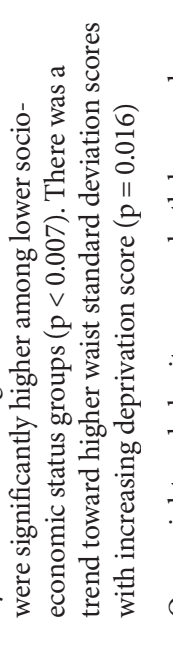

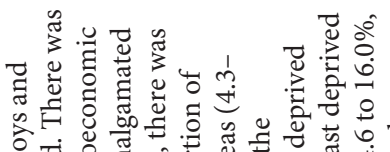

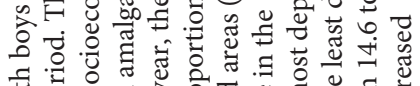

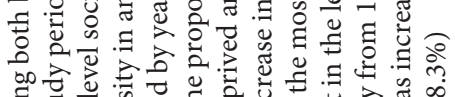
कo

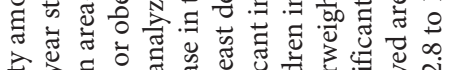

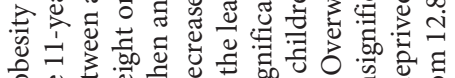

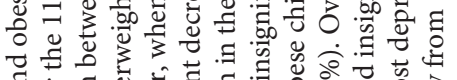

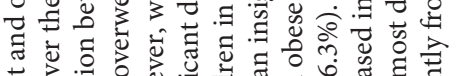

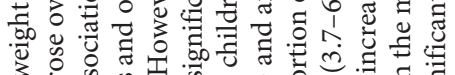

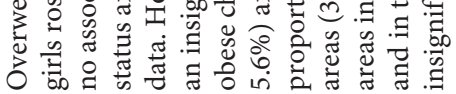
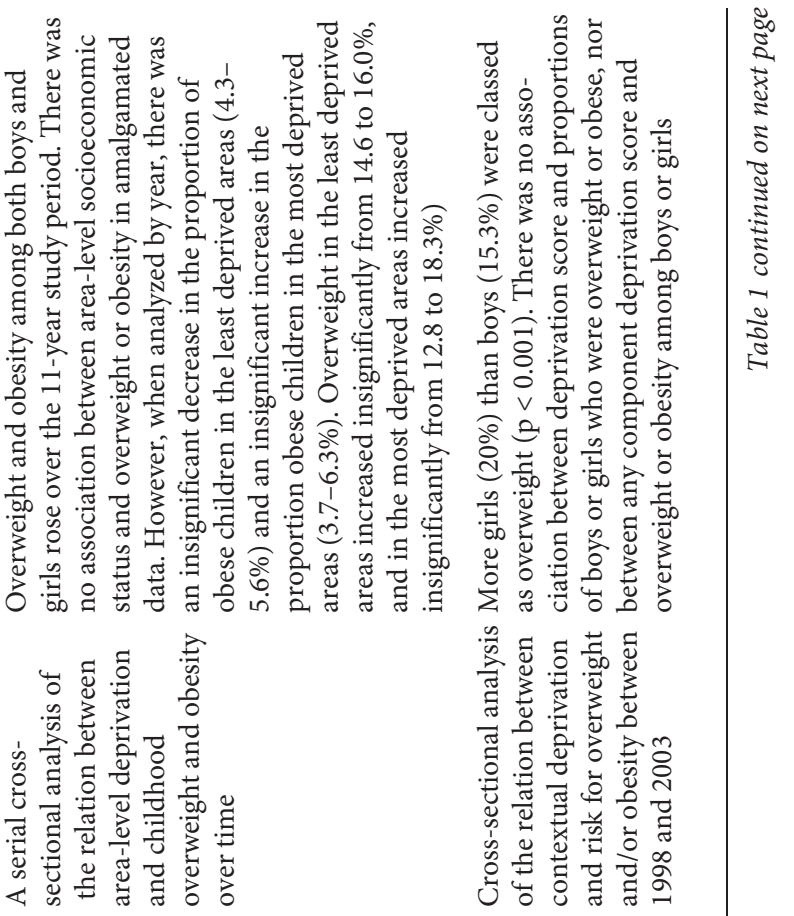

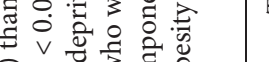
○े ق.

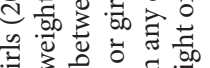
茄

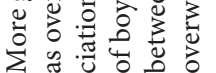

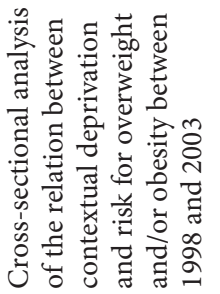

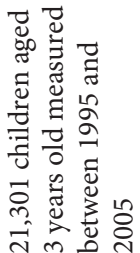

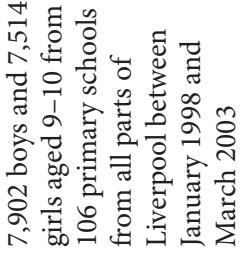

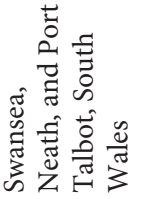

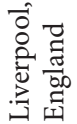

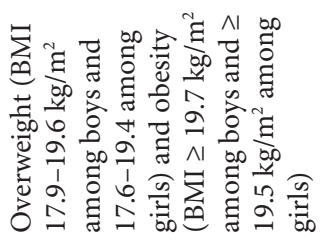

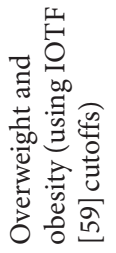

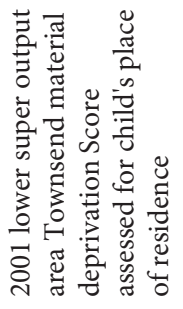<smiles>C1C2C3C1C1C2C31</smiles>

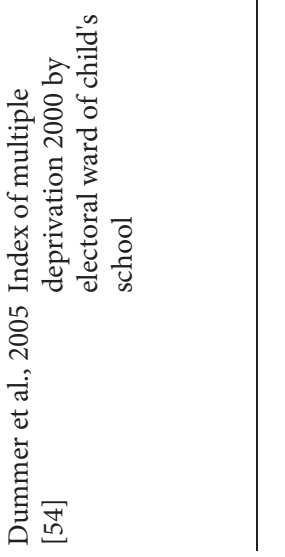


El-Sayed et al.: Socioeconomic Inequalities in Childhood Obesity in the United Kingdom: A Systematic Review of the Literature

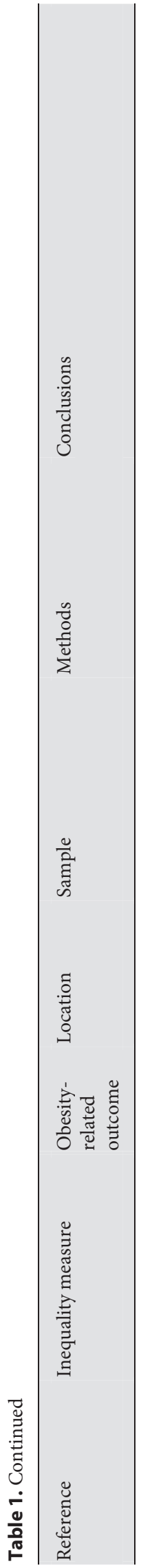

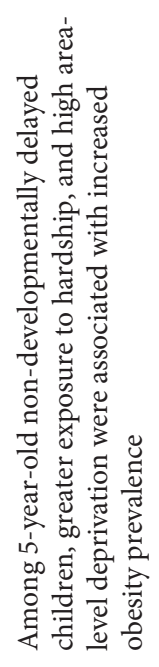

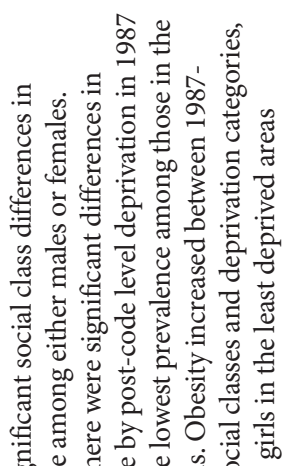

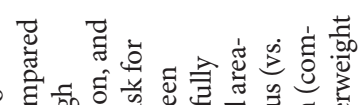

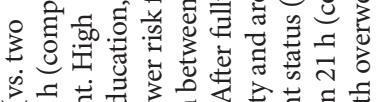

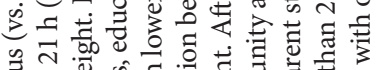

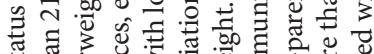
कै

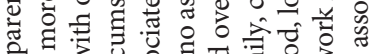

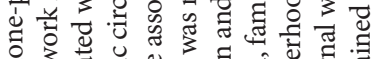

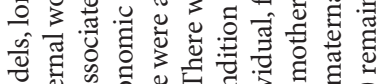

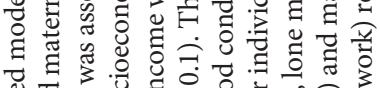

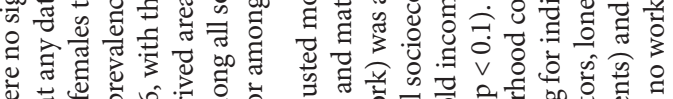

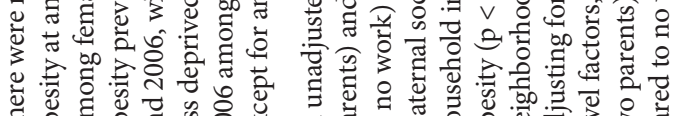

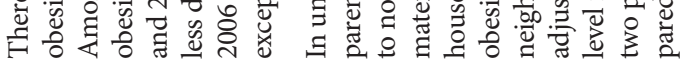

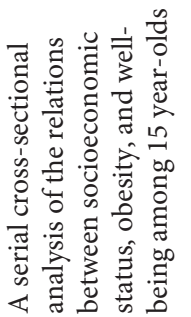

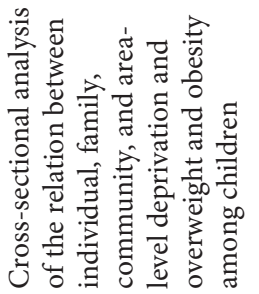

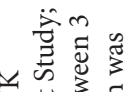

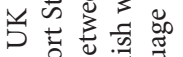
\% 응

잉

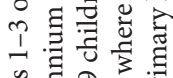

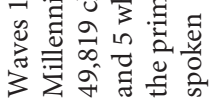
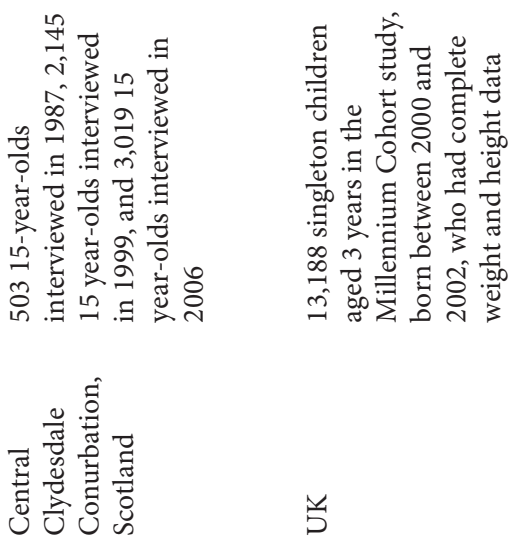

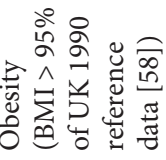

要

要

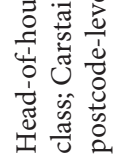

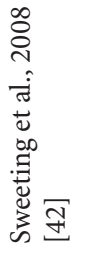

䒓

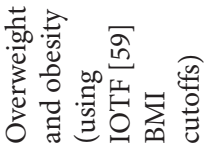

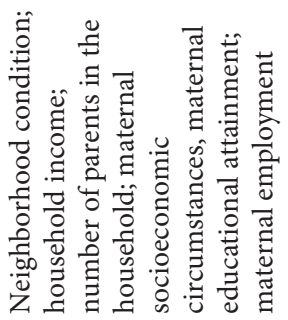

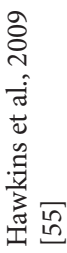

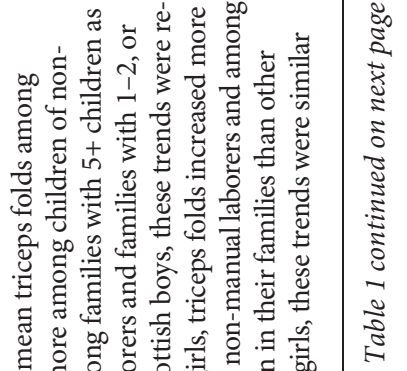

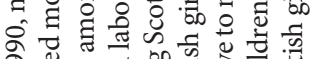

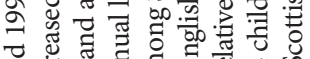

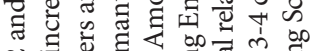
Nล⿵人一

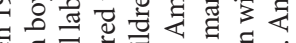

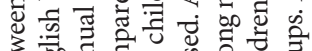

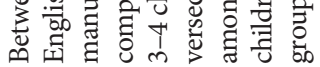

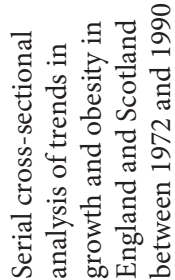

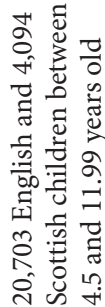

泀

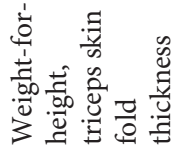

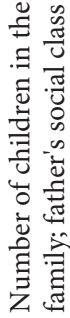

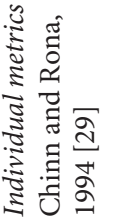




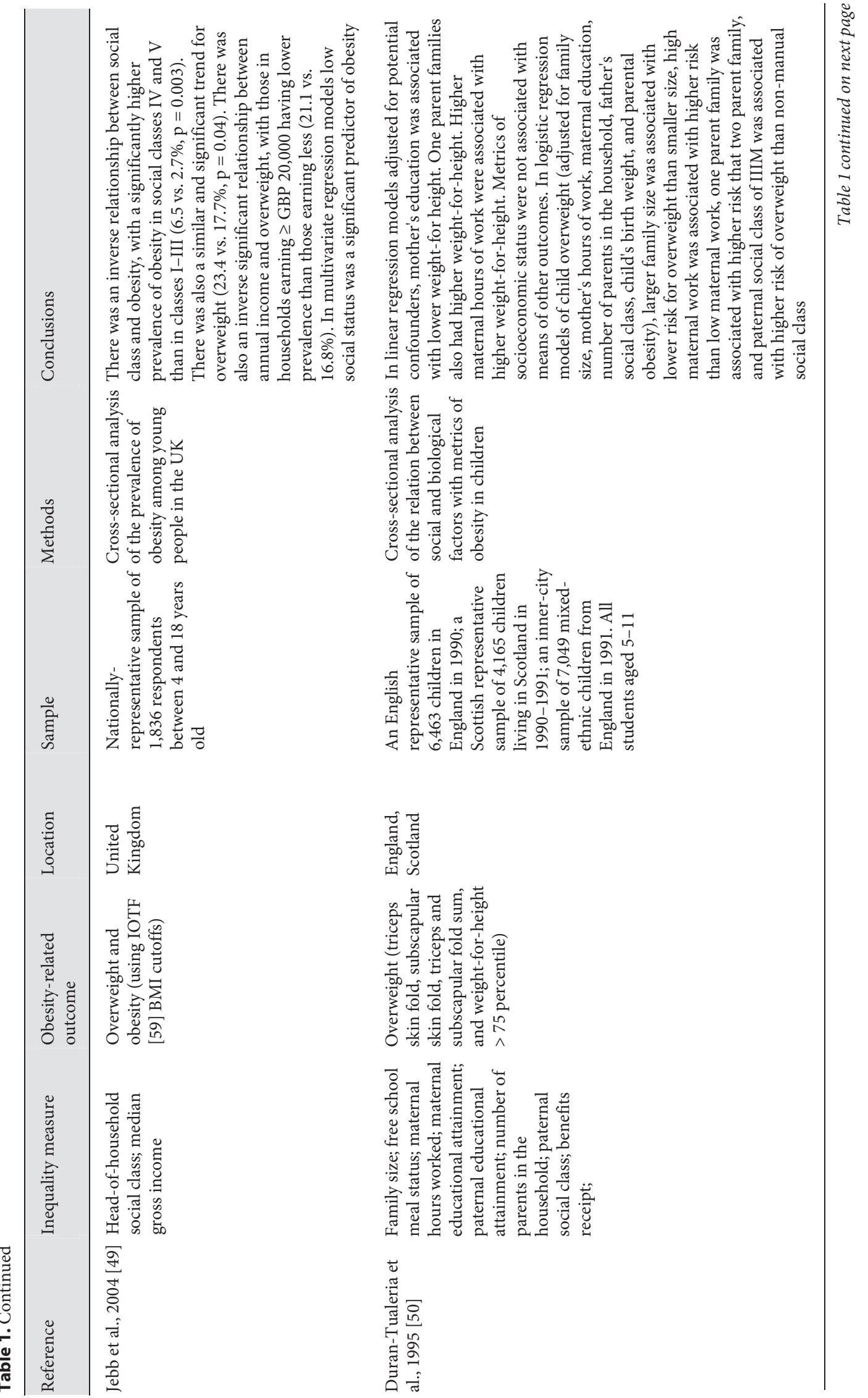




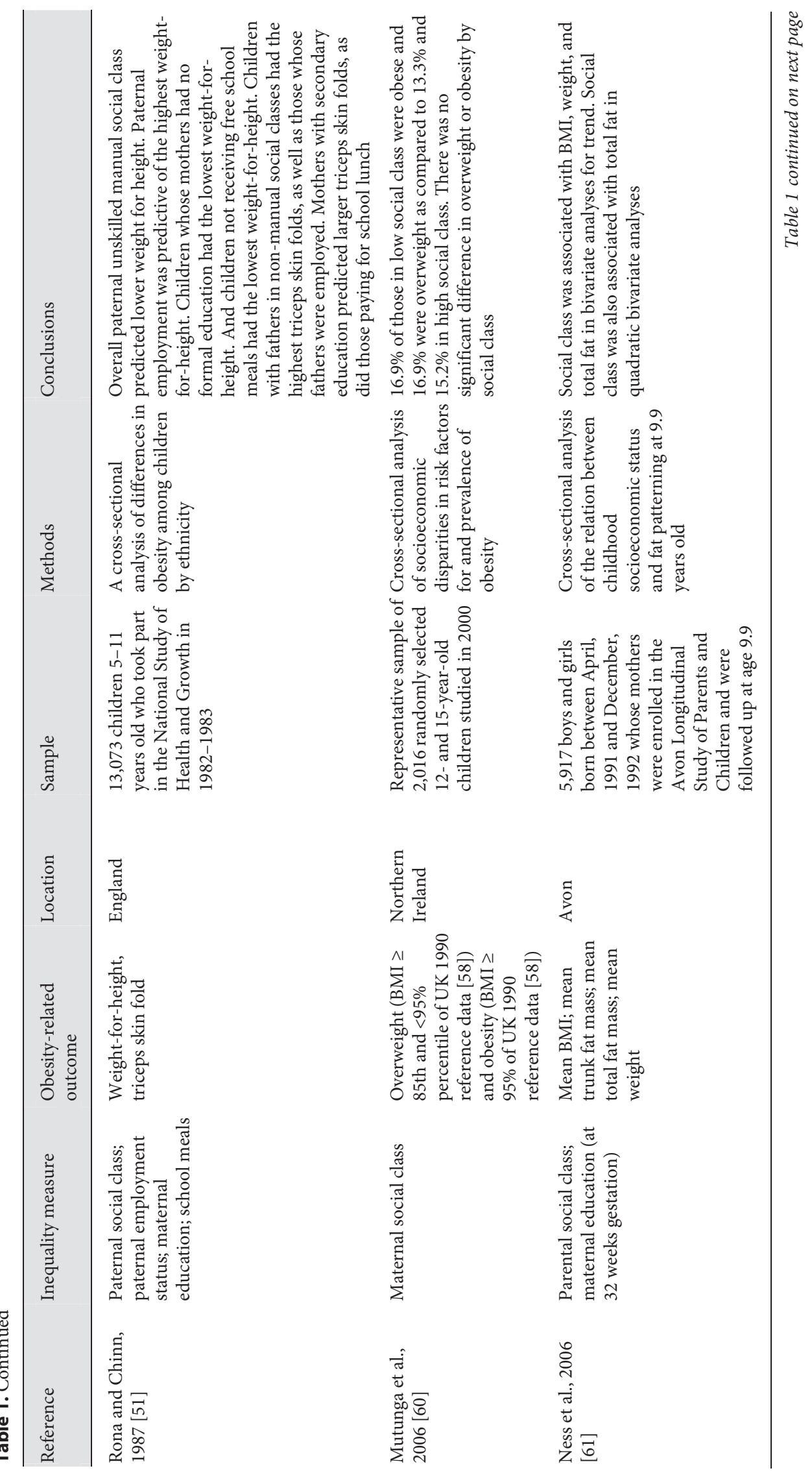



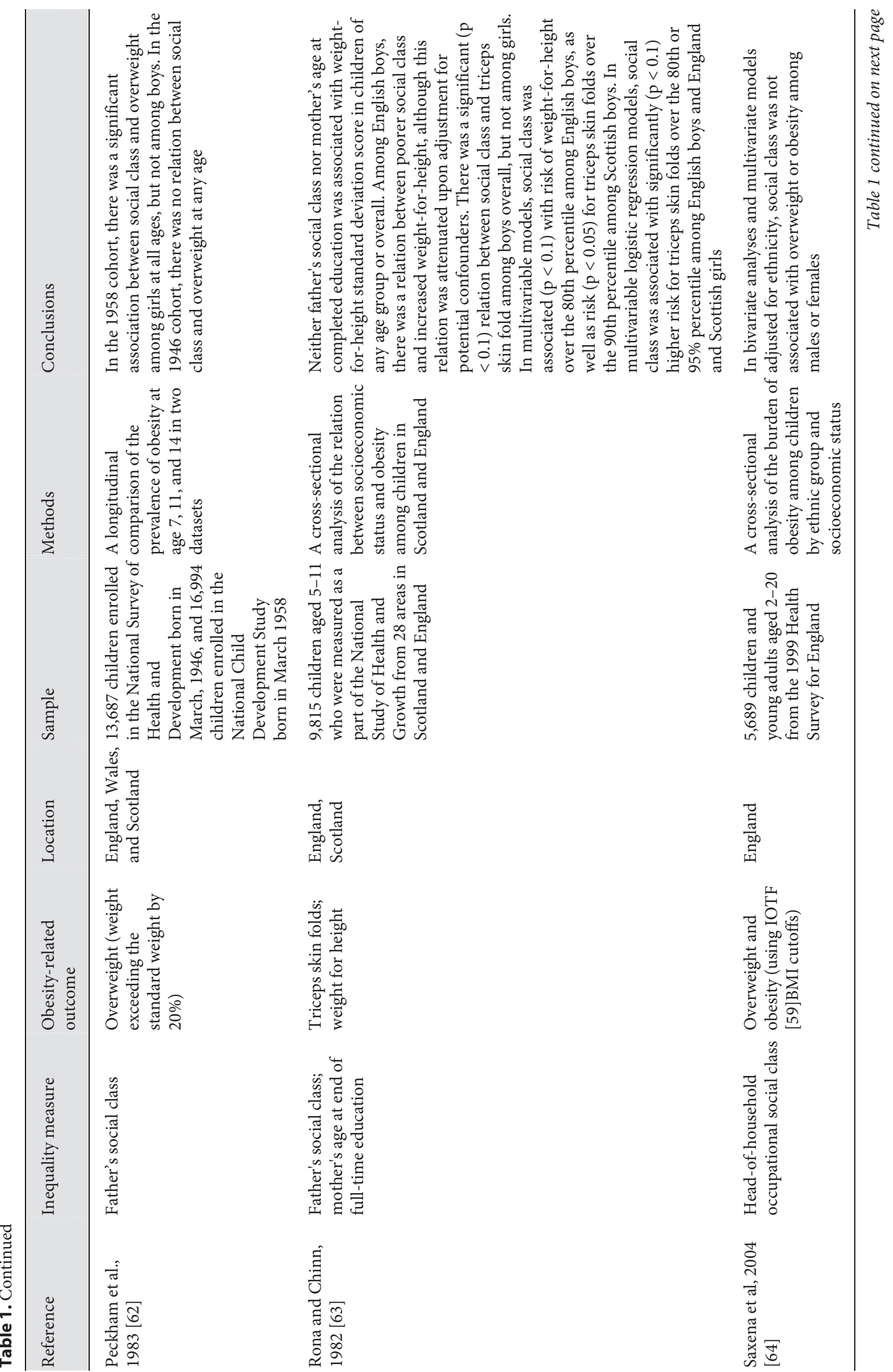

กิ

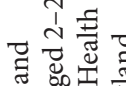

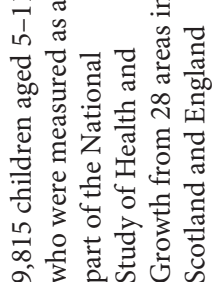

द

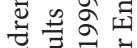

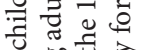

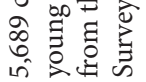

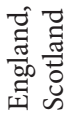

$\overrightarrow{0}$
ज्ञ
ज्ञ
ज्ञ

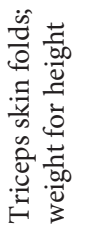




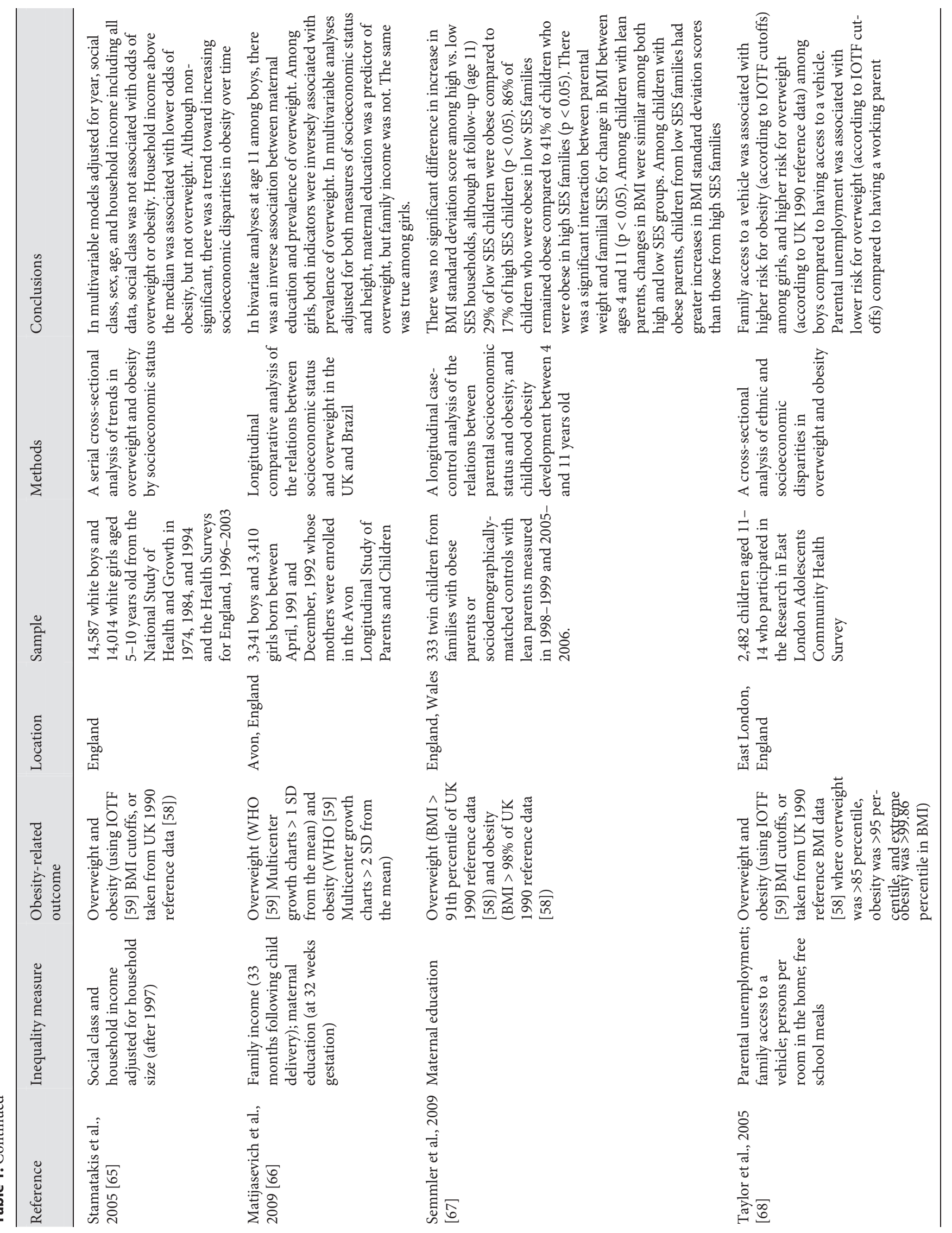




\section{Area-Level Metrics of SEP and Childhood Obesity}

Ten studies assessed the relation between area-level indices of SEP and obesity among children in the UK. The majority (7) of studies assessing area-level SEP metrics and prevalence of obesity among children found that higher area-level deprivation was positively associated with obesity prevalence [37-43], although 3 studies found no association [5355]. Three studies used the Indix of Multiple Deprivation, 3 studies used the Townsend Deprivation Index [56], 2 studies used the Carstairs Deprivation Index [57], 1 study used a school-based metric, and 1 used a neighborhood condition metric as indices of area-level of SEP.

\section{Townsend Deprivation Index}

Of the 3 studies that assessed area-level deprivation via the Townsend Deprivation Index, two found significant associations between deprivation and obesity [39, 43], and one found no association [53]. Kinra and colleagues [39] studied the relation between 1991 enumeration district Townsend material deprivation scores and obesity (BMI $>$ 98th percentile of UK 1990 reference curves [58]) and found a direct relationship between deprivation and obesity risk, as girls and boys in the highest deprivation quartile had 1.39 (95\% CI 1.08-1.80) and 1.29 (95\% CI 1.00-1.65) higher odds of obesity, respectively, than their least deprived counterparts. Wardle and colleagues [43] found similar results among 5,863 students from 36 schools in London. Brunt and colleagues [53] studied the relation between 2001 residence lower super output area Townsend material deprivation scores [56] and overweight (BMI 17.9-19.6 kg/m² among boys and 17.6-19.4 kg/m $\mathrm{m}^{2}$ among girls) and obesity (BMI $\geq 19.7 \mathrm{~kg} / \mathrm{m}^{2}$ among boys and $\geq 19.5 \mathrm{~kg} / \mathrm{m}^{2}$ among girls) among 21,301 children aged 3 years old in Swansea, Neath, and Port Talbot in the South of Wales between 1995 and 2005. Although they found no significant relationship between deprivation scores and obesity risk, they found that there was a non-significant decrease in obesity among the least deprived, and a similar increase among the most deprived between 1995 and 2005.

\section{Index of Multiple Deprivation}

Among the three studies that assessed area-level deprivation via the Index of Multiple Deprivation, two found significant associations between deprivation and obesity [40, 41], and one found no association [54]. Emerson [41] assessed the relation between area-level Index of Multiple Deprivation and risk for obesity (using International Obesity Taskforce (IOTF) BMI cutoffs [59]) among 48,819 children in the Millennium Cohort Study. He found that high area-level deprivation was associated with increased obesity prevalence. Rutter [40] found similar results in a data briefing about 2006-2007 data from the UK-wide National Child Measurement Programme. Dummer and colleagues [54] used the Index of Multiple Deprivation to assess SEP disparities in overweight and obesity (using IOTF BMI cutoffs [59]) among over 15,000 9- and 10-year-old children in Liverpool. They found no association between area-level deprivation and overweight or obesity among boys or girls.

\section{Carstairs-Morris Deprivation Index}

Two studies utilized the Carstairs-Morris Deprivation Index to assess SEP disparities in childhood obesity, and both found that higher deprivation was predictive of higher obesity risk [37, 42]. Armstrong and colleagues [37] assessed the relation between Carstairs Deprivation Index and prevalence of overweight (BMI > 95\% percentile relative to UK 1990 reference data) or obesity (BMI $>98 \%$ percentile relative to UK 1990 reference data [58]) among a representative sample of 74,500 children aged 39-42 months in Scotland. In their sample, $4.7 \%$ of children were obese in the highest deprivation category compared to $3.7 \%$ 
in the lowest category. They found that after adjusting for child birth weight, those in the highest deprivation category had 1.43 higher odds (95\% CI 1.16-1.77) of obesity compared to those with the lowest category. Sweeting and colleagues [42] assessed the relation between Carstairs-Morris postcode-level deprivation and obesity (BMI > 95\% of UK 1990 reference data [58]) among 15-year-old Scottish children in 1987, 1999, and 2006. Among females, there were significant differences in obesity prevalence by post-code level deprivation in 1987 and 2006, with lower prevalence among those in less deprived settings. There were no differences among males.

\section{Miscellaneous}

One study used a school-based metric to assess SEP disparities in childhood obesity and showed a positive association between deprivation and obesity prevalence [38], and another used a neighborhood condition metric and found no association [55]. Cecil and colleagues [38] studied 1,240 boys and 1,214 girls between 4 and 10 years old from 47 primary schools in eastern Scotland. Using a school-based metric based on the number of students entitled to free school meals by school, they found that there was an inverse association with material wellbeing and overweight and obesity (both using IOTF BMI cutoffs [59]) risk among boys and girls. Hawkins and colleagues [55] studied 13,188 singletons from the Millennium Cohort Study. Using IOTF BMI cutoffs [59], they found no association between neighborhood condition, an index of objective measures of neighborhood deprivation, and obesity risk.

\section{Household and Individual-Level Metrics of SEP and Childhood Obesity}

There were 16 studies that assessed the relations between household and/or individuallevel metrics of SEP and obesity prevalence among children in the UK. Among them, there were 15 different household-level and individual-level SEP metrics assessed as determinants of obesity. Eleven studies assessed the relation between head-of-household occupational social class and obesity prevalence [29, 42, 49-51, 60-65]. Seven assessed the relation between maternal education and obesity prevalence [50, 51, 55, 61, 63, 66, 67]. Four studies assessed the relation between parental employment and obesity risk [51, 55, 68]. Three each assessed relationships between household income $[55,65,66]$ or receiving free school meals $[50,51,68]$ and obesity prevalence. Two studies considered the number of people in the household as a determinant of obesity $[29,50]$. Other household and individual metrics of SEP included material deprivation score [41], paternal education [50], number of parents in the household [55], household benefits receipt [50], access to a vehicle [68], and household overcrowding [68].

\section{Occupational Social Class}

The literature about the relation between head-of-household occupational social class and obesity risk generally suggests that low social class is associated with higher risk for obesity. Among studies that utilized this SEP metric, 7 found that social class was inversely associated with obesity risk [29, 49, 50, 60-63]. For example, among a nationally representative sample of children between 4 and 18 years of age from throughout the UK, Jebb and colleagues [49] found an inverse relationship between social class and obesity (according to IOTF BMI cutoffs [59]), with a significantly higher prevalence of obesity in social classes IV and $\mathrm{V}$ than in classes I-III ( 6.5 vs. $2.7 \%, \mathrm{p}=0.003$ ).

One study found that head-of-household occupational social class was positively associated with obesity risk [51], Chinn and Rona [29] assessed trends in triceps skin folds 
among 20,703 English and 4,094 Scottish 4.5- to 12-year-old children between 1972 and 1990. They found that among boys in England, non-manual paternal social class was associated with higher increases in triceps skin folds than manual social class, but they found the opposite among girls as well as among both boys and girls in Scotland.

However, 3 studies found no association between head-of-household social class and obesity risk [42, 64, 65]. For example, Saxena and colleagues [64] found no association between the exposure and obesity (using IOTF BMI cutoffs [59]) among 5,689 children aged 2-20 years sampled in the 1999 Health Survey for England.

\section{Maternal Education}

The literature about the relation between maternal education and childhood obesity suggests that low maternal education is an important predictor of childhood obesity. Among 7 studies that assessed this relation, four found a significant inverse association between maternal education and the outcome of interest [50,51, 61, 66, 67]. For example, one study by Semmler and colleagues [67] found that, although there was no significant difference in increase in overweight (BMI> 91st percentile according to UK 1990 reference data [58]) or obesity (BMI > 98th percentile of UK 1990 reference data [58]) between 1998/1999 and 2005/2006 by maternal education among 333 twin children in a 7-year longitudinal study in England and Wales, at last follow-up (age 11 years) 29\% of low SEP children were obese compared to $17 \%$ of high SEP children $(p<0.05) .86 \%$ of children who were obese in low SEP families remained obese at follow-up compared to $41 \%$ of children who were obese in high SEP families $(\mathrm{p}<0.05)$. Both findings were statistically significant.

One study found a positive association between maternal education and childhood obesity risk. Duran-Tauleria and colleagues [50] found that in adjusted models, increasing maternal education was predictive of higher weight-for-height and higher risk for overweight (weight-for-height $>75 \%$ percentile, according to UK 1990 reference data [58]).

There were two studies that found no association between maternal education and childhood obesity [55, 63]. Hawkins and colleagues [55] found no association between maternal education and overweight or obesity (according to IOTF BMI cutoffs [59]) among 13,188 3-year-old singleton children. Rona and Chinn [63] found similar results assessing the relation between maternal age at completion of education and triceps skin folds and weight-for-height among 9,815 children aged 5-11 years in Scotland and England.

\section{Parental Employment}

Four studies assessed relationships between parental employment and obesity risk among children [50,51, 55, 68]. Among 13,188 3-year-old singleton children, Hawkins and colleagues [55] found that, while maternal employment itself was not associated with overweight (IOTF BMI cutoffs [59]), children of mothers working $21 \mathrm{~h} /$ week or greater had 1.23 higher odds (95\% CI 1.10-1.37) of overweight. Similarly, Duran-Tauleria and colleagues [50] found that higher working hours among mothers were associated with higher weight-for-height among English, Scottish, and inner-city samples aged 5-11 years. Another study among 2,482 children in East London found that parental unemployment was associated with lower risk for overweight (IOTF BMI cutoffs [59]) compared to parental employment [68]. Similarly, in a 1982-1983 study of 13,073 5- to 11-year-old children, paternal employment was predictive of higher weight-for-height than paternal unemployment [51].

\section{Household Income}

Three studies also assessed the relation between household income and obesity risk $[55,65,66]$. Only one study found an association: Stamatakis and colleagues [65] found that 
household income adjusted for family size was associated with lower odds of obesity (using IOTF BMI cutoffs [59]) in fully adjusted models among data from the National Studies of Health and Growth in 1974, 1984 and 1994, and the 1996-2003 Health Surveys for England. Among 13,188 3-year-old singleton children, Hawkins and colleagues [55] found no association between household income and overweight (IOTF BMI cutoffs [59]) in bivariate models, although there was a tendency toward overweight among lower income households $(\mathrm{p}=$ 0.11). Matijasevich and colleagues [66], in a study of just under 7,000 children in Avon, reported a non-significant $(\mathrm{p}<0.06)$ association between household income and overweight among boys, and no association among girls.

\section{Free School Meals}

Three studies also assessed the relation between receiving free school meals and risk for childhood obesity. They found no association between free school meals and obesity risk $[50,51,68]$. For example, Taylor and colleagues [68] showed no association between receiving free school meals and overweight or obesity (using both IOTF BMI cutoffs [59] and 1990 UK reference data [58]) among 2,482 11- to 14-year-old children in East London. However, it is important to note that two of the extant studies are derived from data older than 15 years, and one is limited to a highly diverse sample in East London, and therefore may not accurately reflect the relation between receiving free school meals and childhood obesity risk in the UK. Moreover, because free school meals in the UK are allocated based on household income, adjusting for other socioeconomic metrics in multivariable models of this relation may be methodologically questionable, although this was done in each of the studies reviewed here.

\section{Household Size}

Two studies considered the number of people in the household as a determinant of obesity [29,50], with conflicting findings. One study [50] found in fully adjusted models that larger family size was protective against overweight (weight-for-height above the 75th percentile according the UK 1990 reference data [58]). Alternatively, Chinn and Rona [29] found that a higher number of children in the family was associated with higher mean triceps skin fold increase between 1972 and 1990 among English boys, but found the opposite among Scottish boys, and English and Scottish girls.

\section{Miscellaneous}

Other household and individual metrics of SEP that were studied as predictors of childhood obesity included material deprivation [41], paternal education [50], number of parents in the household [55], household benefits reception [50], access to a vehicle [68], and household persons per room [68]. Of these, material deprivation [41] number of parents in the household [55], and access to a vehicle [68] were associated with any outcome of interest.

Emerson [41] studied the relation between an individual metric of material deprivation (using the number of consumer durable goods deemed 'essentials' not present in the household) and obesity risk (using IOTF BMI cutoffs [59]), and found that greater exposure to material deprivation was associated with obesity risk. Hawkins and colleagues [55], among 13,188 singletons from the Millennium Cohort Study, found that lone-parent status was associated with overweight (using IOTF BMI cutoffs [59]) risk in fully adjusted models. Taylor and colleagues [68], in a study of almost 2,500 East London children aged 11-14 years, found that family access to a vehicle was associated higher risk for obesity (according to IOTF BMI cutoffs [59]) among girls, and higher risk for overweight (according to UK 1990 reference data [58]) among boys compared to having no access to a vehicle. 
El-Sayed et al.: Socioeconomic Inequalities in Childhood Obesity in the United

Kingdom: A Systematic Review of the Literature

\section{Discussion}

A comprehensive review of the peer-reviewed literature regarding socioeconomic inequalities in childhood obesity in the UK between 1980 and 2010 found that both arealevel and household/individual-level metrics of SEP are associated with childhood obesity in the UK. In particular, three of the most common area-level indices of SEP in the epidemiologic literature, the Index of Multiple Deprivation, the Townsend Deprivation Index [56], and the Carstairs Deprivation Index [57], were reliable predictors of childhood obesity in the UK (although they did not predict obesity in all studies). We also found that common household and individual-level metrics of childhood SEP, including head-of-household social class and maternal education were reliable determinants of childhood obesity in the UK (although they did not predict obesity in all studies). Some other associated household and individuallevel metrics, including household income, free school meals, and paternal employment, were not independently associated with childhood obesity after adjustment for income levels. This indicates the importance of supporting analyses with appropriate conceptual casual frameworks that specify the production of inequalities in obesity across levels and therefore guide the construction of analytic models when exploring the roles of socioeconomic predictors of childhood obesity at the area level, household level, and individual level.

While there are relatively few prospective studies of the relation between SEP and obesity in other Western European countries, their findings are comparable to the small number of which we are aware in the UK. For example, in a prospective study of 341 children aged between 6 and 8 years in the south of Italy, Valerio and colleagues [69] demonstrated that children with less educated mothers had accelerated weight gain over a 3-year period relative to those with more educated mothers. A prospective study of a random sample of 9- and 10-year-old children in Copenhagen schools in Denmark [70] found that, while parental education and occupation did not predict obesity at 10 years follow-up after adjusting for childhood adiposity and gender, a metric of neighborhood-level deprivation predicted higher risk for overweight after adjustment for parental education and occupation. Similarly, in a prospective cohort of 10-year-old children in Sweden [71], low neighborhood-level social class was associated with higher obesity risk. By contrast, in a cohort of children in Southeast Sweden [72], neither maternal nor paternal education was associated with risk of childhood obesity at age 5 (using IOTF BMI cutoffs [59]).

\section{Methodological Limitations of the Extant Literature}

Although this review demonstrated important gradients in childhood obesity risk by metrics of SEP in the UK, there are several methodological limitations to the current literature about socioeconomic inequalities in childhood obesity that limit our understanding: i) there have been few studies that have simultaneously studied both area-level and household/individual-level determinants of childhood obesity, ii) there are no known studies that have utilized multilevel modeling or complex systems approaches to understand the relative influence of contextual and individual SEP on childhood obesity risk in the UK, iii) there is limited availability of longitudinal studies that have assessed life course and/or intergenerational SEP gradients in childhood obesity, iv) the extant literature has paid little attention to mechanisms underlying the relation between metrics of SEP and childhood obesity, and v) the multiplicity of SEP metrics used in analysis and the lack of adherence to comparable metrics limits comparisons of the literature across metrics.

The first two limitations pose foundational challenges to our understanding of socioeconomic inequalities in childhood obesity in the UK. First, the concept that individuals may 
El-Sayed et al.: Socioeconomic Inequalities in Childhood Obesity in the United

Kingdom: A Systematic Review of the Literature

interact with, and therefore be influenced by, their ecological contexts is fundamental in social scientific inquiry [73-76]. Studies about socioeconomic disparities in childhood obesity which only account for variation in the outcome of interest via individual or household metrics of SEP, of which there were 14 of 23 studies reviewed, may not account for ecological manifestations of poverty and their contributions to childhood obesity, yielding an imperfect understanding of the relation between SEP and childhood obesity.

Moreover, 7 of 23 studies reviewed assessed area-level metrics of SEP as determinants of obesity without including individual-level or household-level metrics of SEP. In the absence of individual-level SEP data, investigators often use area-level SEP metrics as proxies for individual SEP. However, area-level SEP metrics are encumbered by substantial measurement error, as not all individuals living in lower SEP areas will have low individual SEP metrics, and vice versa. Moreover, it is difficult to ascertain the mechanisms that relate area-level metrics of SEP to health outcomes of interest. On one hand, area-level SEP metrics can serve as proxies for individual SEP, thereby representing populations with concentrated individual-level poverty, and explaining relations between area-level metrics and outcomes of interest. Alternatively, it is possible that context itself, independent of individual-level SEP, can predict outcomes of interest [73].

Studies that simultaneously consider both individual and area-level factors as determinants of outcomes are most appropriate, given the following three barriers discussed above: i) Individuals may interact with, and therefore be influenced by, their ecological contexts [73-76]. ii) Area-level SEP variables may be poor proxies for individual-level SEP. iii) It is difficult to quantify the direct and indirect contributions of area-level metrics to outcomes of interest in epidemiologic analyses that do not include individual-level data. Epidemiologists, therefore, have begun, over the past 10 years, to conceptualize and analyze models of disease with such a multilevel understanding in mind [77] - a departure from traditional models of disease that focused on features of the individual or proxies thereof exclusively [78]. Multilevel models, which account for clustering within multilevel data, allow investigators to estimate the relations between exposures and outcomes of interest while adjusting for other exposures across levels of influence [73]. Multilevel thinking has allowed investigators to conceptualize and examine how factors operating at multiple levels of influence - characteristics of individuals, their families, contacts, neighborhoods, and societies - can shape, both individually and in cooperation, their health and disease risks [77]. Growing out of the multilevel conceptual paradigm as well as an understanding of the limitations of traditional predictive regression modeling, complex systems approaches feature stochastic modeling techniques that allow investigators to capture bi-directional, dynamic, and relational interactions between traditional 'exposures' and 'outcomes' at any level of analysis and influence [77]. These approaches, therefore, may be ideally suited to understand the causes, mechanisms, and consequences of socioeconomic disparities in childhood obesity in high-income contexts. Without simultaneous study of SEP metrics on multiple levels using multilevel or complex systems tools, it remains impossible to quantify the contributions of metrics of SEP at multiple levels to childhood obesity risk in this context.

The third methodological limitation is the limited availability of longitudinal studies that have assessed life course and/or intergenerational SEP gradients in childhood obesity in the UK. Increasingly, the life course approach has gained traction in social epidemiology. Defined by Ben-Shlomo and Kuh [79], the life course framework in epidemiology implies the assessment of long-term effects on disease risk from physical and social exposures throughout the life course. Life course approaches to the question of childhood obesity in the UK have been fruitful: for example, a study about the predictors of childhood obesity among a cohort of 7-year-old children in Avon [66] found that several exposures occurring before the age of 3, including parental obesity, early adiposity rebound, greater than $8 \mathrm{~h} /$ week spent 
watching television, and short sleep duration at age 3 were all significant predictors of obesity ( $>95$ th percentile of UK 1990 reference data [58]). Moreover, within this framework, evidence has suggested that maternal health and wellbeing, both before and during pregnancy, may influence the health and wellbeing of children. For example, studies have demonstrated that maternal smoking [80] and maternal obesity [81] during pregnancy may influence risk for childhood obesity. The paucity of longitudinal studies that have included and/or analyzed socioeconomic data from gestation and/or early childhood as determinants of obesity in later children in meaningful ways limits our understanding of the mechanisms by which SEP may influence childhood obesity risk in the UK.

Growing out of the paucity of longitudinal studies, the fourth methodological limitation to the extant literature about socioeconomic inequalities in childhood obesity in the UK is that the current literature has largely ignored mechanisms by which SEP may influence childhood obesity. For example, it has been shown that food insecurity may mediate the relation between poor SEP and risk for childhood obesity in other countries, as it may lead to binge eating cycles and energy-dense food consumption $[82,83]$. To our knowledge, this feature of the relation between SEP and obesity among children in the UK remains unstudied. Studies that empirically assess mechanisms by which SEP may influence obesity risk in the UK are crucial for interventions designed to curb the childhood obesity epidemic in this context.

The fifth methodological limitation is that the multiplicity of SEP metrics used in analysis and the lack of adherence to comparable metrics limits comparisons of the literature across metrics. For example, the most regularly studied metric of SEP in the literature reviewed above was head of household social class, about which only 11 out of 23 studies collected and analyzed data. The next most considered metric was maternal education at 7 out of 23 studies. Because the nature of SEP metrics, their relation to childhood obesity, and the mechanism by which they may influence obesity among children may differ substantially, the lack of adherence to comparable metrics among studies assessing SEP differences in childhood obesity risk in the UK disrupts overall comparisons across studies and limits our ability to draw meaningful inference from the extant literature.

\section{Limitations}

The reader should keep in mind several limitations when interpreting the findings of this review. First, because we restricted the studies reviewed above to those published in the peer-reviewed literature, the articles we reviewed and the inferences we have drawn may be subject to a publication bias. Although our inclusion criteria were expansive and included data about many of the largest health surveys in the UK, our findings may not accurately reflect current knowledge about SEP and obesity in the UK. Second, our findings were organized by level of influence and then by metric of analysis. Our organization scheme could possibly have, in part, shaped the inferences we drew from the extant literature. Third, our findings were limited to studies about socioeconomic disparities in obesity risk among children in the UK. Therefore, it would be inappropriate to generalize our findings to other age groups in other national contexts.

\section{Directions for Future Research}

Five directions for future research emerge from this review. First, studies that assess SEP metrics at multiple levels of influence - area, household, and individual - are needed to understand the complex relation between SEP and childhood obesity risk. 
Second, these studies should utilize multilevel thinking during conception and multilevel and complex systems approaches during analysis so as to quantify SEP influences at multiple levels on childhood obesity risk. These studies could clarify the importance of contextual factors in shaping childhood obesity in the UK for researchers and policymakers alike.

Third, investigators interested in this area might consider studies that include data about maternal SEP during pregnancy as well as early life metrics of SEP among children so as to understand SEP determinants of childhood obesity in the UK throughout the life course.

Fourth, research about the mechanisms relating SEP and childhood obesity in the UK is needed so as to educate potential interventions against childhood obesity.

Fifth, consensus regarding metrics of SEP that are most fruitful in research about socioeconomic disparities in childhood obesity is needed, and researchers in this area should utilize these metrics primarily.

\section{Acknowledgement}

This study was funded in part by the British Heart Foundation and the Rhodes Trust.

\section{Disclosure Statement}

The authors claim no conflicts of interest.

\section{References}

Caballero B: The global epidemic of obesity: an overview. Epidemiol Rev 2007;29:1-5.

2 de Onis M, Blossner M, Borghi E: Global prevalence and trends of overweight and obesity among preschool children. Am J Clin Nutr 2010;92:1257-1264.

3 Wang Y, Lobstein T: Worldwide trends in childhood overweight and obesity. Int J Pediatr Obes 2006;1: 11-25.

4 World Health Organization: Obesity and Overweight Fact Sheet. Fact sheet N 311, May 2012.www.who.int/ mediacentre/factsheets/fs311/en/ (last accessed September 21, 2012).

5 Guo SS, Chumlea WC: Tracking of body mass index in children in relation to overweight in adulthood. Am J Clin Nutr 1999;70:145S-148S.

6 Whitaker RC, Wright JA, Pepe MS, Seidel KD, Dietz WH: Predicting obesity in young adulthood from childhood and parental obesity. N Engl J Med 1997;337:869-873.

- 7 Freedman DS, Khan LK, Dietz WH, Srinivasan SR, Berenson GS: Relationship of childhood obesity to coronary heart disease risk factors in adulthood: the Bogalusa Heart Study. Pediatrics 2001;108:712-718.

- 8 Lumeng JC, Forrest P, Appugliese DP, Kaciroti N, Corwyn RF, Bradley RH: Weight status as a predictor of being bullied in third through sixth grades. Pediatrics 2010;125:e1301-1307.

9 Boutelle KN, Hannan P, Fulkerson JA, Crow SJ, Stice E: Obesity as a prospective predictor of depression in adolescent females. Health Psychol 2010;29:293-298.

-10 Gunnell DJ, Frankel SJ, Nanchahal K, Peters TJ, Davey Smith G: Childhood obesity and adult cardiovascular mortality: a 57-y follow-up study based on the Boyd Orr cohort. Am J Clin Nutr 1998;67:1111-1118.

11 Must A, Strauss RS: Risks and consequences of childhood and adolescent obesity. Int J Obes Relat Metab Disord. 1999;23(suppl 2):s2-s11.

12 Wilson PWF, D’Agostino RB, Sullivan L, Parise H, Kannel WB: Overweight and obesity as determinants of cardiovascular risk: the Framingham experience. Arch Intern Med 2002;162:1867-1872.

13 Wellman NS, Friedberg B: Causes and consequences of adult obesity: health, social and economic impacts in the United States. Asia Pac J Clin Nutr 2002;11:705-709.

14 Mokdad AH, Ford ES, Bowman BA, Dietz WH, Vinicor F, Bales VS, Marks JS: Prevalence of obesity, diabetes, and obesity-related health risk factors, 2001. JAMA 2003;289(1):76-79.

15 Veer P, Kampman E: Food, Nutrition, Physical Activity and the Prevention of Cancer: a Global Perspective. Washington, D.C., World Cancer Research Fund/ American Institute for Cancer Research, 2007. 
El-Sayed et al.: Socioeconomic Inequalities in Childhood Obesity in the United

Kingdom: A Systematic Review of the Literature

16 Calle EE, Rodriguez C, Walker-Thurmond K, Thun MJ: Overweight, obesity, and mortality from cancer in a prospectively studied cohort of US adults. N Engl J Med 2003;348:1625-1638.

17 Møller H, Mellemgaard A, Lindvig K, Olsen JH: Obesity and cancer risk: a Danish record-linkage study. Eur J Cancer 1994;30:344-350.

-18 Suk SH, Sacco RL, Boden-Albala B, Cheun JF, Pittman JG, Elkind MS, Paik MC, Northern Manhattan Stroke Study: Abdominal obesity and risk of ischemic stroke: the Northern Manhattan Stroke Study. Stroke 2003; 34:1586-1592.

19 Coggon D, Reading I, Croft P, McLaren M, Barrett D, Cooper C: Knee osteoarthritis and obesity. Int J Obes 2001;25:622-627.

20 Onyike CU, Crum RM, Lee HB, Lyketsos CG, Eaton WW: Is obesity associated with major depression? Results from the Third National Health and Nutrition Examination Survey. Am J Epidemiol 2003;158:1139-1147.

21 Lynch JW, Kaplan GA: Socioeconomic position; in Berkman LF, Kawachi I (eds): Social Epidemiology. New York, Oxford University Press, 2000, pp 13-35.

22 Link BG, Phelan J: Social conditions as fundamental causes of disease. J Health Soc Behav 1995;Spec No:8094.

23 McLaren L: Socioeconomic status and obesity. Epidemiol Rev 2007;29:29-48.

24 Ball K, Crawford D: Socioeconomic status and weight change in adults: a review. Soc Sci Med 2005;60: 1987-2010.

-25 Sobal J, Stunkard AJ: Socioeconomic status and obesity: a review of the literature. Psychol Bull 1989;105: 260-275.

26 Prentice AM: The emerging epidemic of obesity in developing countries. Int J Epidemiol 2005;35:93-99.

27 Bell AC, Ge K, Popkin BM: The road to obesity or the path to prevention: motorized transportation and obesity in China. Obesity 2002;10:277-283.

28 Seidell J: Obesity: a growing problem. Acta Paediatr Suppl 1999;88:46-50.

$\checkmark 29$ Chinn S, Rona RJ: Trends in weight-for-height and triceps skinfold thickness for English and Scottish children, 1972-1982 and 1982-1990. Paediatr Perinat Epidemiol 1994;8:90-106.

30 National Health Service Information Centre: Health Survey for England 2007. Latest Trends 2008. www. ic.nhs.uk/statistics-and-data-collections/health-and-lifestyles-related-surveys/health-survey-for-england/healthsurvey-for-england-2007-latest-trends-\%5Bns\%5D (last accessed September 21, 2012).

-31 Poobalan AS, Aucott LS, Ahmed S, Smith WC: Analysis of the UK recommendations on obesity based on a proposed implementation framework. BMC Public Health 2010;10:17.

32 National Institute for Health and Clinical Excellence: NICE Public Health Guidance 17: Promoting Physical Activity, Active Play and Sport for Pre-School and School-Age Children and Young People in Family, PreSchool, School and Community Settings. 2009. http://guidance.nice.org.uk/PH17 (last accessed September 21, 2012).

-33 Mackenbach JP, Stirbu I, Roskam A-R, Schaap MM, Menvielle G, Leinsalu M, Kunst AE: Socioeconomic inequalities in health in 22 European countries. N Engl J Med 2008;358:2468-2481.

-34 Marmot MG, Smith GD, Stansfeld S, Patel C, North F, Head J, White I, Brunner E, Feeney A: Health inequalities among British civil servants: the Whitehall II study. Lancet 1991;337:1387-1393.

35 Marmot, MG: Fair Society, Health Lives: Strategic Review of the Health Inequalities in England post2010(The Marmot Review). 2010 www.ucl.ac.uk/gheg/marmotreview (last accessed September 21, 2012)

-36 Mackenbach JP: Widening socioeconomic inequalities in mortality in six Western European countries. Int J Epidemiol 2003;32:830-837.

37 Armstrong J, Dorosty AR, Reilly JJ, Emmett PM, Child Health Information Team: Coexistence of social inequalities in undernutrition and obesity in preschool children: population based cross sectional study. Arch Dis Child 2003;88:671-675.

-38 Cecil JE, Watt P, Murrie IS, Wrieden W, Wallis DJ, Hetherington MM, et al: Childhood obesity and socioeconomic status: a novel role for height growth limitation. Int J Obes (Lond) 2005;29:1199-1203.

39 Kinra S, Nelder RP, Lewendon GJ. Deprivation and childhood obesity: a cross sectional study of 20,973 children in Plymouth, United Kingdom. J Epidemiol Community Health 2000;54:456-460.

40 Rutter H: Data briefing. Child obesity worst in deprived areas. Health Serv J 2008:21.

$\checkmark 41$ Emerson E: Overweight and obesity in 3- and 5-year-old children with and without developmental delay. Public Health 2009;123:130-133.

42 Sweeting H, West P, Young R: Obesity among Scottish 15 year olds 1987-2006: prevalence and associations with socio-economic status, well-being and worries about weight. BMC Public Health 2008;8:404.

-43 Wardle J, Brodersen NH, Cole TJ, Jarvis MJ, Boniface DR: Development of adiposity in adolescence: five year longitudinal study of an ethnically and socioeconomically diverse sample of young people in Britain. BMJ 2006;332:1130-1135.

44 Dinsdale H, Ridler C: National Child Measurement Programme: Changes in Children's Body Mass Index between 2006/07 and 2008/09. Oxford, National Obesity Observatory, 2010.

45 Her Majesty's Government: PSA Delivery Agreement 12: Improve the Health and Wellbeing of Children and Young People 2008. London, PSA Delivery Agreement 2007, pp 1-34. http://www.londonhp.nhs.uk/ wp-content/uploads/2011/03/PSA-Delivery-Agreement-12.pdf (last accessed September 21, 2012). 
El-Sayed et al.: Socioeconomic Inequalities in Childhood Obesity in the United

Kingdom: A Systematic Review of the Literature poverty.pdf (last accessed September 21,2012).

47 Department for Children, Schools and Family: Obesity; 2010. http://webarchive.nationalarchives.gov. uk/20100202084034/dcsf.gov.uk/everychildmatters/healthandwellbeing/informationforlocalauthorities/obesity/ (last accessed September 21, 2012).

-48 Balakrishnan R, Webster P, Sinclair D: Trends in overweight and obesity among 5-7-year-old White and South Asian children born between 1991 and 1999. J Public Health (Oxf) 2008;30:139-144.

49 Jebb SA, Rennie KL, Cole TJ: Prevalence of overweight and obesity among young people in Great Britain. Public Health Nutr 2004; 7:461-465.

50 Duran-Tauleria E, Rona RJ, Chinn S: Factors associated with weight for height and skinfold thickness in British children. J Epidemiol Community Health 1995;49:466-473.

51 Rona RJ, Chinn S: National Study of Health and Growth: social and biological factors associated with weightfor-height and triceps skinfold of children from ethnic groups in England. Ann Hum Biol 1987;14:231-248.

52 Chinn S, Hughes JM, Rona RJ: Trends in growth and obesity in ethnic groups in Britain. Arch Dis Child 1998; 78:513-517.

53 Brunt H, Lester N, Davies G, Williams R: Childhood overweight and obesity: is the gap closing the wrong way? J Public Health (Oxf) 2008;30:145-152.

54 Dummer TJ, Gibbon MA, Hackett AF, Stratton G, Taylor SR: Is overweight and obesity in 9-10-year-old children in Liverpool related to deprivation and/or electoral ward when based on school attended? Public Health Nutr 2005;8:636-641.

-55 Hawkins SS, Cole TJ, Law C, Millennium Cohort Study Child Health Group: An ecological systems approach to examining risk factors for early childhood overweight: findings from the UK Millennium Cohort Study. J Epidemiol Community Health 2009;63:147-155.

56 Townsend P: Health and deprivation (1997) inequality and the North; in Soothill K, Mackay L, and Malia L (eds): Classic Texts in Health Care. Oxford, Reed Educational and Professional Publishing, Ltd., 1997, pp

57 Carstairs V, Morris R: Deprivation and health in Scotland. Health Bull 1990;48:162-175.

-58 Cole TJ, Freeman JV, Preece MA: Body mass index reference curves for the UK, 1990. Arch Dis Child 1995; 73:25-29.

$\$ 59$ Cole TJ: Establishing a standard definition for child overweight and obesity worldwide: international survey. BMJ 2000;320:1240-1243.

60 Mutunga M, Gallagher AM, Boreham C, Watkins DC, Murray LJ, Cran G, Reilly JJ: Socioeconomic differences in risk factors for obesity in adolescents in Northern Ireland. Int J Pediatr Obes 2006;1:114-119.

61 Ness AR, Leary S, Reilly J, Wells J, Tobias J, Clark E, Smith GD, ALSPAC Study Team: The social patterning of fat and lean mass in a contemporary cohort of children. Int J Pediatr Obes 2006;1:59-61.

62 Peckham CS, Stark O, Simonite V, Wolff OH: Prevalence of obesity in British children born in 1946 and 1958. BMJ 1983;286:1237-1242.

63 Rona RJ, Chinn S: National study of health and growth: social and family factors and obesity in primary schoolchildren. Ann Hum Biol 1982;9:131-145.

64 Saxena S, A mbler G, Cole TJ, Majeed A: Ethnic group differences in overweight and obese children and young people in England: cross sectional survey. Arch Dis Child 2004;89:30-36.

65 Stamatakis E, Primatesta P, Chinn S, Rona R, Falascheti E: Overweight and obesity trends from 1974 to 2003 in English children: what is the role of socioeconomic factors?. Arch Dis Child 2005;90:999-1004.

-66 Matijasevich A, Victora CG, Golding J, Barros FC, Menezes AM, Araujo CL, Smith GD: Socioeconomic position and overweight among adolescents: data from birth cohort studies in Brazil and the UK. BMC Public Health 2009;9:105.

67 Semmler C, Ashcroft J, van Jaarsveld CH, Carnell S, Wardle J: Development of overweight in children in relation to parental weight and socioeconomic status. Obesity (Silver Spring) 2009;17:814-820.

-68 Taylor SJ, Viner R, Booy R, Head J, Tate H, Brentnall SL, Haines M, Bhui K, Hillier S, Stansfeld S: Ethnicity, socio-economic status, overweight and underweight in East London adolescents. Ethn Health 2005;10: 113-128.

69 Valerio G, D’Amico 0, Adinolfi M, Munciguerra A, D’Amico R, Franzese A: Determinants of weight gain in children from 7 to 10 years. Nutr Metab Cardiovasc Dis 2006;16:272-278.

70 Lissau-Lund-Sørensen I, Srensen TI: Prospective study of the influence of social factors in childhood on risk of overweight in young adulthood. Int J Obes 1992;16:169-175.

71 Mériaux BG, Hellström AL, Mårild S: Identification and follow-up of obesity in ten-year-old school children. Int J Pediatr Obes 2008;3:102-108.

72 Huus K, Ludvigsson JF, Enskar K, Ludvigsson J: Exclusive breastfeeding of Swedish children and its possible influence on the development of obesity: a prospective cohort study. BMC Pediatr 2008;8:42.

73 Diez-Roux AV: Multilevel analysis in public health research. Annu Rev Public Health 2000;21:171-192.

-74 Blalock HM: Contextual-effects models: theoretical and methodological issues. Annu Rev Sociol 1984;10: 353-372. 
DiPrete TA, Forristal JD: Multilevel models: methods and substance. Annu Rev Sociol 1994;20:331-357. Hox JJ, Kreft IGG: Multilevel analysis methods. Sociol Methods Res 1994;22:283-299.

Galea S, Hall C, Kaplan GA: Social epidemiology and complex system dynamic modelling as applied to health behaviour and drug use research. Int J Drug Policy 2009;20:209-216.

78 Baker EA, Metzler MM, Galea S: Addressing social determinants of health inequities: learning from doing. Am J Public Health 2005;95:553-555.

79 Ben-Shlomo Y, Kuh D: A life course approach to chronic disease epidemiology: conceptual models, empirical challenges and interdisciplinary perspectives. Int J Epidemiol 2002;31:285-293.

80 von Kries R, Toschke AM, Koletzko B and Slikker W Jr: Maternal smoking during pregnancy and childhood obesity. Am J Epidemiol 2002;156:954-961.

81 Whitaker RC, Wright JA, Pepe MS, Seidel KD, Dietz WH: Predicting preschooler obesity at birth: the role of maternal obesity in early pregnancy. Pediatrics 2004;114:e29-e36.

-82 Casey PH, Simpson PM, Gossett JM, Bogle ML, Champagne CM, Connell C, Harsha D, McCabe-Sellers B, Robbins JM, Stuff JE, Weber J: Children in food-insufficient, low-income families: prevalence, health, and nutrition status. Arch Pediatr Adolesc Med 2001;155:508-514.

-83 Casey PH, Simpson PM, Gossett JM, Bogle ML, Champagne CM, Connell C, Harsha D, McCabe-Sellers B, Robbins JM, Stuff JE, Weber J: The association of child and household food insecurity with childhood overweight status. Pediatrics 2006;118:e1406-e1413 